Insight Bacteriology 1 (1): 1-6, 2012

ISSN 2044-8961 / DOI: 10.5567/BACTERIOL-IK.2012.1.6

(C) 2012 Insight Knowledge, UK

\title{
Screening of Keratinolytic Bacteria from the Feather Dumping Site of Sivakasi
}

\author{
${ }^{1}$ T. Sivakumar, ${ }^{1}$ V. Ramasubramanian, ${ }^{2}$ V.T. Arasu, ${ }^{1}$ T. Shankar and ${ }^{1}$ D. Prabhu \\ ${ }^{1}$ Department of Microbiology, Ayya Nadar Janaki Ammal College (Autonomous), \\ Sivakasi-626124, India \\ ${ }^{2}$ Department of Plant Biology and Plant Biotechnology, \\ Ayya Nadar Janaki Ammal College (Autonomous), Sivakasi-626124, India
}

\begin{abstract}
The aim of this study was to screening and isolation of keratin degrading microorganism from chicken feather dumping site. Three different feather dumping soils samples were taken from Sivakasi area for this study. These three different soils were serially diluted and plated for screening of efficient protease producing microorganism. The zone of protease activity of the isolates determined on skim milk agar medium varied from 5 to $20 \mathrm{~mm}$. Among them, one strain TS2 were produced higher level of zone of 20 and by its protease production. Keratinase assay was carried out by inoculating the eleven isolates individually in feather minimal medium with keratin as a sole source of carbon and nitrogen. Further, Azokeratin assay was performed with $24 \mathrm{~h}$ culture supernatant for TS2. Maximum keratinase specific activity was observed for TS2 $\left(41 \pm 0.5 \mathrm{U} \mathrm{mL}^{-1}\right)$. Further, the selected strain TS2 was identified by various physical, biochemical characters and it was confirmed Bacillus thuringiensis TS2 by $16 \mathrm{~S}$ rDNA Sequences.
\end{abstract}

Key words: Feather waste, keratin, keratinase, $16 \mathrm{~S}$ rRNA

\section{INTRODUCTION}

A myriad of microorganisms, mostly fungi and bacteria, have been identified and reported to utilize keratin, by many authors (Rai et al., 2010). Keratin is degradable by some species of saprophytic and parasitic fungi (Anbu et al., 2005), actinomycetes (Lin et al., 1995), some Bacillus spp. (Lin et al., 1992), Streptomyces pactum DMS 40530, (Kumar and Takagi, 1999) Streptomyces fradiae ATCC 14544(Williams et al., 1990). Observing natural degradation and parasitization of keratinous substrates, as well as duplication of the process under laboratory conditions, suggest the feasibility of biotechnological processing for improving the utilization of feather as animal feed protein. The application of microbial technology for feather processing holds the following nutritional significance. First, culturing of the microorganisms and keratinase activity may result in a modification of the structure of feather keratin. This may alter its resistance to digestive enzymes of the consuming animals (Elmayergi and Smith, 1971).

Biotechnological approaches involving microorganisms and their enzymes appear a conceptually appropriate processing technology. However, there is no compendious literature on the prospects for industrial applications of keratinolytic microorganisms, especially with emphasis on their production of keratinases, properties of keratinases, mechanism (s) and limitations of keratinolysis. Therefore, we reviewed recent information on microbial keratinolysis is reviewed in order to stimulate the application of the biotechnology in feather processing as animal feedstuff. The upgrading of feather nutritional value should yield a high-protein feedstuff that may greatly spare the use of soybean and fish meal in livestock diets. Furthermore, bioconversion of feather will predictably benefit the poultry industry, man and the environment. It was mainly focused on the screening and isolation of keratin degrading microorganism from chicken feather dumping site.

\section{MATERIALS AND METHODS}

Collection of sample: The soil sample was collected from the feather dumping site at Sivakasi, Tamil Nadu, India. Soil sample was collected by using sterile scalpel, at $4 \mathrm{~cm}$ depth and transferred to sterile polythene bag. Then this sample was used for further microbiological analysis.

Serial dilution method (Cappuccino and Sherman, 1999): The soil sample was serially diluted i.e., making 10 fold dilutions. One gram of soil sample was mixed with $99 \mathrm{~mL}$ of sterile distilled water in the conical flask, which

Corresponding Author: T. Sivakumar, Department of Microbiology, Ayya Nadar Janaki Ammal College (Autonomous), Sivakasi- 626124, India Tel: +919443310246 
gave a dilution procedure was performed up to $10^{-10}$ of dilutions. The diluted samples were used for the isolation of bacterial species.

Isolation of bacterial species: The sterilized plate with nutrient agar medium was prepared and marked with respective dilutions. With the help of sterile pipettes, $0.1 \mathrm{~mL}$ of the diluted sample was kept on Petri plate rotator and with the help of sterilized L-rod, the sample was evenly spread. The plates were incubated at $37^{\circ} \mathrm{C}$ for $24 \mathrm{~h}$.

Screening on skim milk agar: Skim milk agar medium was sterilized at $121^{\circ} \mathrm{C}$ for $15 \mathrm{~min}$ at $15 \mathrm{lbs}$ pressure. The isolates were streaked on the medium. The zone formed around the colonies due to production of caseinase enzyme, was considered as positive result. The organisms screened with skim milk agar medium were sub cultured by growing the bacterium in nutrient broth medium at $37^{\circ} \mathrm{C}$ for $24 \mathrm{~h}$.

Screening and selection of keratinolytic bacterial strains: Skim milk plates were prepared for primary screening of bacteria that produced proteases. The selected protease producing bacteria were subsequently grown in feather consisted of $\left(\mathrm{g} \mathrm{L}^{-1}\right) ; \mathrm{NaCl}-0.5$; $\mathrm{MgCl}_{2} \cdot 6 \mathrm{H}_{2} \mathrm{O}-0.1 ; \mathrm{CaCl}_{2}-0.06 ; \mathrm{KH}_{2} \mathrm{PO}_{4}-0.7 ; \mathrm{K}_{2} \mathrm{HPQ}-1.4$ and feather- $1 \mathrm{~g} ; \mathrm{pH}$ of the medium adjusted to 7.0 (using $1 \mathrm{~N}$ $\mathrm{NaOH}$ ) in which feather were the only sources of carbon and nitrogen (Lin et al., 1995). Cultures were grown at $37^{\circ} \mathrm{C}$ at $120 \mathrm{rpm}$ for $24 \mathrm{~h}$. Keratinolytic strains that completely broke down feathers in the medium were selected.

Enzymatic hydrolysis of azokeratin (keratinase assay): This procedure tested the keratinolytic activity of keratinase on azo-keratin. To begin the process, $5 \mathrm{mg}$ of azo-keratin was added to a $1.5 \mathrm{~mL}$ centrifuge tube along with $0.8 \mathrm{~mL}$ of $50 \mathrm{mM}$ potassium phosphate buffer $(\mathrm{pH} 7.5)$ at $37^{\circ} \mathrm{C}$ for $1 \mathrm{~h}$ with constant agitation $(900 \mathrm{rpm})$. This mixture was agitated until the azo-keratin was completely suspended. A $0.2 \mathrm{~mL}$ aliquot of supernatant of crude enzyme was added to the azo-keratin, mixed and incubated for $15 \mathrm{~min}$ at $50^{\circ} \mathrm{C}$ with shaking. The reaction was terminated by adding $0.2 \mathrm{~mL}$ of $10 \%$ trichloroacetic acid (TCA). The reaction mixture was filtered and analyzed for activity.

The absorbance of the filtrate was measured at $450 \mathrm{~nm}$ with a UV-160 spectrophotometer. A control sample was prepared by adding the TCA to a reaction mixture before the addition of enzyme solution. The unit of keratinase activity was defined as a 0.01 unit increase in the absorbance at $450 \mathrm{~nm}$ as compared to the control after $15 \mathrm{~min}$ of reaction (Burtt and Ichida, 1999).
Identification of feather degrading bacteria by morphological characterization: Efficient feather degrading bacteria was identified based on the morphological, cultural and biochemical characteristics. Biochemical test was performed in $\mathrm{KBOO} 2 \mathrm{Hi}^{\text {Assorted }}{ }^{\mathrm{TM}}$ Biochemical Kit. Carbohydrate fermentation test was performed in $\mathrm{KBOO} 9 \mathrm{Hi}$ Carbohydrate ${ }^{\mathrm{TM}} \mathrm{Kit}$ (HiMedia). $16 \mathrm{~S}$ ribosomal RNA (rRNA) gene sequencing.

PCR on the extracted DNA was performed on 100 Volume. Oligonucleotide primers with specificity for eubacterial 16S rRNA genes, primers $16 \mathrm{~S}$ rDF (CGCTGGCGGCAGGCTTAACA); $16 \mathrm{~S}$ rDR (CCAGCCGCAGGTTCCCCT) were used to amplify the 16S rRNA gene fragments with template DNA originating from bacteria. The following conditions were used for DNA amplification: 35 cycles consisting of denaturation at $94^{\circ} \mathrm{C}$ for $0.5 \mathrm{~min}$, annealing at $55^{\circ} \mathrm{C}$ for $1 \mathrm{~min}$ and extension at $72^{\circ} \mathrm{C}$ for $1.5 \mathrm{~min}$ followed by a final extension at $72^{\circ} \mathrm{C}$ for $3 \mathrm{~min}$. Amplified PCR products of proper size (about 1500 base pair fragment) were confirmed by gel electrophoresis of $1 \mathrm{~L}$ samples through a $1 \%$ horizontal agarose gel electrophoresis containing $0.5 \mathrm{~g} \mathrm{~mL}^{-1}$ ethidium bromide. Gels were viewed under UV light and photographed.

PCR products were purified using QIA quick Spin columns (Qiagen Inc., Chatsworth, CA). A Perkin Elmer 377 DNA sequencer, in combination with Dye deoxy Terminator Cycle sequencing Kit (Perkin, Foster City, CA) was used for sequencing the purified PCR products by the help of MWG bio informatics centre. Nucleotide sequencing was compared with sequences in the National Centre for Biotechnology Information (NCBI). Gen bank database using the BLASTn program and Ribosomal Database Project (RDP) database using the sequence matching program.

Phylogenetic analysis: Identical 16S rDNA sequence were recognized by analysis of phylogenetic trees and manual comparisons, in which sequence with more than $90 \%$ similarity were defined as identical, and these sequences were used for further phylogenetic analysis as Operational Taxonomic Unit (OUT). All sequences were submitted to GenBank for preliminary analysis using the program BLAST (http://www.ncbi.nlm.nih.gov/BLAST) to identify putative close phylogenetic relatives. Distance based evolutionary trees were constructed using the neighbor joining algorithm.

\section{RESULTS}

Isolation and screening of keratinolytic bacteria from feather dumping soil: Three different feather dumping soils samples were taken from Sivakasi area for this study these three different soils were serially diluted and plated for screening of efficient protease producing 


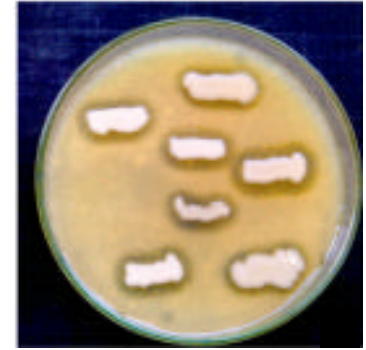

Fig. 1: Isolation of protease producing microbes from feather dumping soil using skim milk agar

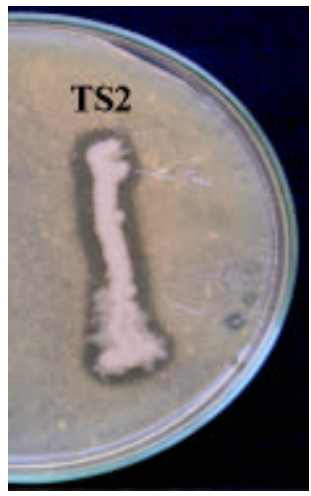

Fig. 2: Selection of protease producing microbes from feather dumping soil using skim milk agar

microorganism. After $24 \mathrm{~h}$ incubation the plates were kept at $37^{\circ} \mathrm{C}$. Out of nineteen isolates eleven strains exhibited protease activity were further confirmed by skim milk agar and therefore they were used for further study. They were designated as namely TS1, TS2, TS6, TS9, TS11, TS12, TS13, TS14, TS15, TS17 and TS19. The zone of protease activity of the isolates on skim milk agar medium varied from 5 to $20 \mathrm{~mm}$ (Fig. 1). Among them strain TS2 produced higher level of zone of $20 \mathrm{~mm}$ by its protease production.

Keratinase activity of bacterial isolates: Keratinase assay was carried out by inoculating the eleven isolates individually in feather minimal medium with keratin as a sole source of carbon and nitrogen. Initially the cultures were selected based on the feather degradation ability in the medium. Among 11 isolates four of them were positively degrade the feather in the medium. Further, Azokeratin assay was performed with $24 \mathrm{~h}$ culture supernatant. Based on the keratin assay experiment isolate TS2 strain showed higher for keratinase activity. Maximum keratinase specific activity was observed for TS2 produced $\left(41 \pm 0.5 \mathrm{U} \mathrm{mL}^{-1}\right)$. TS2 was selected for further analysis (Fig. 2).

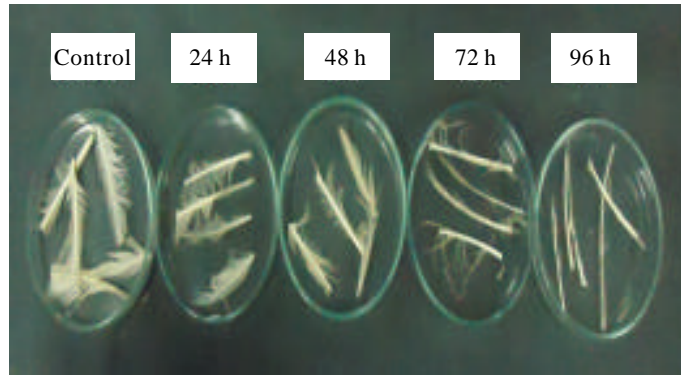

Fig. 3: Feather degradation efficiency of the isolates (TS2) at various time intervals

Table 1: Morphological and biochemical characteristics of TS2

\begin{tabular}{|c|c|}
\hline Cultural characters & TS2 \\
\hline \multicolumn{2}{|l|}{ Morphology } \\
\hline Colony property & $\begin{array}{l}\text { On nutrient agar, colonies are circular, smooth } \\
\text { round, waxy, slight yellow to white and mucoid, } \\
\text { produces no pigment }\end{array}$ \\
\hline Spores staining & $\begin{array}{l}\text { Ellipsoidal and cylindrical, central subterminal, } \\
\text { swelling the sporangium }\end{array}$ \\
\hline Gram's staining & Gram positive rod \\
\hline Motility & Motile \\
\hline \multicolumn{2}{|c|}{ Biochemical characters } \\
\hline Indole production test & + \\
\hline Methyl red test & + \\
\hline Voges-Proskauer test & + \\
\hline Catalase & + \\
\hline Gelatin liquefaction & + \\
\hline Caseinase & + \\
\hline Starch hydrolysis & + \\
\hline
\end{tabular}

+ : Positive result

Effect of various incubation times of bacterial isolates for keratinase production: Selected microbes were inoculated into feather minimal medium for feather degradation at different time intervals. This experiment was carried out in Feather minimal medium supplemented with feather as substrate. After inoculation, it was periodically checked at different time intervals of $24,48,72$ and $96 \mathrm{~h}$ at $37^{\circ} \mathrm{C}$ with $250 \mathrm{rpm}$. The maximum activity was observed for TS2 in $96 \mathrm{~h}$ (Fig. 3).

Identification of strains based on biochemical and cultural characteristics: The selected strain TS2 was identified by various physical, biochemical and molecular characterization analysis. The strain was Gram positive, rod shaped, endospore forming, and motile bacteria. According to Bergey's manual of Determinative Bacteriology, the selected microbes were identified as Bacillus TS2 sp. All the carbon utilizing and biochemical studies were tested using $\mathrm{KB} 0002 \mathrm{Hi}$ assorted TM Biochemical kit and KB009 Hicarbohydrate kit and results were presented (Table 1-3).

Identification of strains based on 16S rDNA gene: The 16S rDNA gene of the Bacillus sp. strains TS2 was amplified using Polymerase Chain Reaction (PCR) with the 
Table 2: Biochemical results for TS2 by $\mathrm{KBOO} 2 \mathrm{Hi}$ Assorted $^{\mathrm{TM}}$ biochemical kit

\begin{tabular}{lc}
\hline Biochemical tests & TS2 strain \\
\hline Citrate utilization & + \\
Lysine decarboxylase & + \\
Ornithine & + \\
Decarboxylase & - \\
Urease & - \\
Phenyl alanine & + \\
Deamination & - \\
Nitrate reduction & + \\
$\mathrm{H}_{2}$ S production & - \\
Glucose & + \\
Adonitol & - \\
Lactose utilization & + \\
Arabinose utilization & + \\
Sorbitol & + \\
\hline
\end{tabular}

+: Positive, -: Negative

Table 3: Carbohydrate fermentation tests for TS2 by KBOO9 Hi carbohydrate ${ }^{\mathrm{TM}}$ kit

\begin{tabular}{|c|c|}
\hline Carbohydrate & TS2 strain \\
\hline Lactose & + \\
\hline Xylose & + \\
\hline Maltose & + \\
\hline Fructose & - \\
\hline Dextrose & + \\
\hline Galactose & + \\
\hline Raffinose & - \\
\hline Trehalose & + \\
\hline Mellibiose & - \\
\hline Sucrose & + \\
\hline L-arabinose & + \\
\hline Mannose & + \\
\hline Inulin & + \\
\hline Sodium gluconate & + \\
\hline Glycerol & + \\
\hline Salicin & - \\
\hline Glucosamine & + \\
\hline Inositol & - \\
\hline Sorbitol & - \\
\hline Manitol & + \\
\hline Adonitol & - \\
\hline$\alpha$ methyl D-glucoside & - \\
\hline Ribose & + \\
\hline Rhamnose & - \\
\hline Cellobiose & + \\
\hline Melezitose & - \\
\hline$\alpha$-methyl D-mannoside & - \\
\hline Xylitol & - \\
\hline ONPG & + \\
\hline Esculin & - \\
\hline D-arabinose & + \\
\hline Citrate & - \\
\hline Malanate & + \\
\hline Sorbose & - \\
\hline
\end{tabular}

+: Positive, -: Negative

help of $16 \mathrm{~S}$ rDNA Universal primers. The amplified product was checked in $0.7 \%$ Agarose gel showed the expected size of $1.5 \mathrm{~kb}$. The amplified fragment was eluted and both the strands were sequenced. The sequences were compared against $16 \mathrm{~S}$ rDNA sequences available in the RDP database sequence analysis revealed that the strains were phylogenetically closely related to the

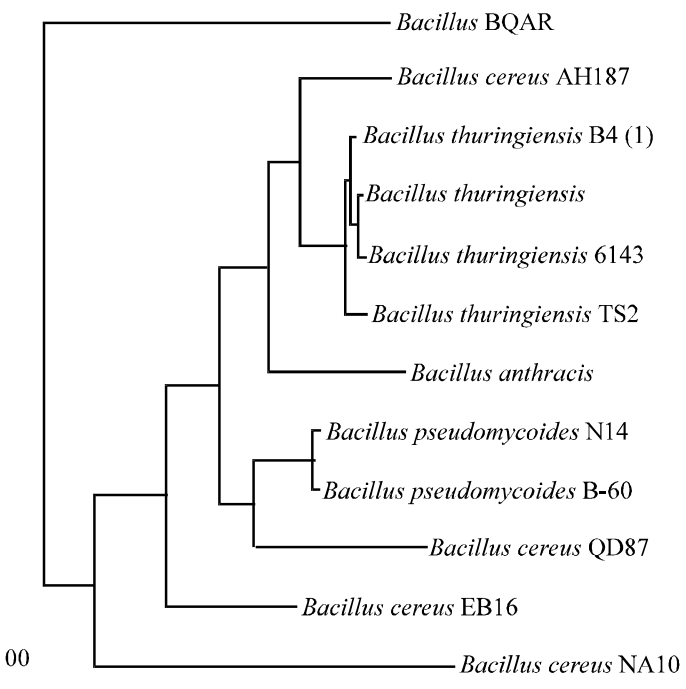

Fig. 4: Phylogenetic analysis of TS2 (Bacillus thuringiensis) and some bacterial strains

genus Bacillus. Blast analysis of the 16S rDNA sequence of TS2 isolate revealed that the selected isolates showed maximum similarity of $92 \%$ with Bacillus thuringiensis.

The Phylogenetic relationship was obtained using neighbor joining by pair wise comparison among the $16 \mathrm{~S}$ rDNA gene sequence of selected TS2 isolate with species. The dendrogram was constructed for their Phylogenetic relationship and it revealed that the isolate TS2 it grouped with in the Bacillus thuringiensis cluster confirmed that it is belongs to Bacillus thuringiensis. The 16S rRNA gene sequences of the isolates had been submitted to the GenBank under the accession number FJ377887 for Bacillus thuringiensis TS2. Further it was confirmed by 16S rDNA sequencing analysis (Fig. 4).

\section{DISCUSSION}

Three different feather dumping soils samples were taken from Sivakasi area for this study. Out of nineteen isolates eleven strains exhibited protease activity were further confirmed by skim milk agar and therefore they were used for further study. They were designated as namely TS1, TS2, TS6, TS9, TS11, TS12, TS13, TS14, TS15, TS17 and TS19. Among them strain TS2 produced higher level of zone of $20 \mathrm{~mm}$ by its protease production. Selected microbe was inoculated into feather minimal medium for feather degradation at different time intervals, the maximum activity was observed for TS 2 in $96 \mathrm{~h}$. The selected strain TS2 was identified by various physical, biochemical and molecular characterization analysis. The strain was Gram positive, rod shaped, endospore forming, 
and motile bacteria. According to Bergey's manual of Determinative Bacteriology, the selected microbes were identified as Bacillus spp. Screening of the strain was very similar to that of the work done by Lin et al. (1995), where the seven proteolytic strains of Bacillus species isolated from canola meal compost; five feather hydrolyzing strains have been identified as Bacillus licheniformis. Arasu et al. (2009) have reported the prevalence of Bacillus sp. among 13 feather degrading strains screened. Eight strains of Bacillus obtained from natural composting sample have shown efficient degradation of wastes and decrease in the feather protein from 13.6 to $1.92 \%$.

In the present study, Bacillus thuringiensis TS2 showed maximum keratinase activity at $96 \mathrm{hrs}$ of growth at $37^{\circ} \mathrm{C}$. In another study, Williams et al. (1990) demonstrated that Bacillus licheniformis PWD-I degrades intact feather completely at $50^{\circ} \mathrm{C}$ in 10 days. Lal et al. (1996) recorded the degradation of child scalp hair by Bacillus subtilis and Bacillus licheniformis strains after 14 days. Suntornsuk et al. (2005) observed that the Bacillus licheniformis FK14 is also to show and degrade feather at $50^{\circ} \mathrm{C}$ in 5 days. Giongo et al. (2007) reported that keratinolytic Bacillus sp. isolated from Brazilian Amazon basin shows considerable degradation after $72 \mathrm{~h}$ of incubation. Recently Ionata et al. (2008) isolated Clostridium sporogenes from solfataric muds which degraded native feather in 7 days. Hence we used Bacillus thuringiensis TS2 as an efficient feather degrading strain.

Radha and Gunasekaren (2008) reported that the Bacillus licheniformis MKU produced maximum keratinase after $48 \mathrm{~h}$ of growth. Similarly Lin et al. (1995) observed maximum level of keratinase production between 48 and $60 \mathrm{~h}$ growth of Bacillus licheniformis strains. El-Refaia et al. (2005) found maximum keratinase activity in B. pumilus $\mathrm{F} 49$ after $48 \mathrm{~h}$ of growth. However, Gupta and Ramnani, (2006) reported increased keratinase activity at $72 \mathrm{~h}$ of growth by Bacillus licheniformis RGI. Microbacterium sp. kr10 produces maximum keratinase activity in raw feather medium at $36 \mathrm{~h}$ coinciding with the end of exponential phase (Thys et al., 2004).

Phenotypic characterization of any microorganism is the first step towards its identification and taxonomic classification. However, many of the microbes from the same genus share overlapping phenotypic characters and therefore, they are difficult to distinguish only on the basis of phenotypic tests (Rai and Mukherjee, 2010; Rai et al., 2010).

Over the years, determination of the phylogenetic relationship or identification of bacteria based on $16 \mathrm{~S}$ rDNA sequencing (ribotyping) has been widely accepted.
On the basis of phylogenetic analysis the AS-S10-II may thus classified as a species of the genus Brevibacillus. Furthermore, Menaquinone-7 isolated from strain AS-S10-11 was also reported to be major quinone in B. limnophilus sp. nov. B. ginsengisoli sp. nov. (Suzuki et al., 2006) and B. panacihumi sp. nov. On the basis of the data obtained from phenotypic, chemotaxonomic and Phylogenetic analyses, the strain AS-S10-11 could not be classified under a known species of the Brevibacillus and the name of this new strain was proposed as Brevibacillus sp. Strain AS-S10-11.

The 16S rRNA gene of the Bacillus spp. strain TS2 was amplified using Polymerase Chain Reaction (PCR) with the help of $16 \mathrm{~S}$ rDNA Universal primers. 16S rDNA sequences available in the RDP database sequence analysis revealed that the strains were phylogenetically closely related to the genus Bacillus. The dendrogram was constructed for their phylogenetic relationship and it revealed that the isolate TS2 it grouped with in the Bacillus thuringiensis cluster Blast analysis of the 16S rDNA sequence of TS2 isolate revealed that the selected isolates showed Maximum similarity of $92 \%$ with Bacillus thuringiensis. The 16S rRNA gene sequences of the isolates had been submitted to the GenBank under the accession number FJ377887 for Bacillus thuringiensis TS2. Bacillus thuringiensis TS2 was considered as the potential keratinolytic strain. The most effective keratin degrading strains in the Bacillus sp. belongs to Bacillus licheniformis (Manczinger et al., 2003).

\section{REFERENCES}

Anbu, P., S.C.B. Gopinath, A. Hide, T.L. Priya and G. Annadurai, 2005. Purification of keratinase from poultry farm isolate-Scopulariopsis brevicaulis and statistical optimization of enzyme activity. Enz. Microbial. Technol., 36: 639-647.

Arasu, V.T., T. Sivakumar, V. Ramasubramanian, K. Nalini and R. Kiruthiga, 2009. The potential application of keratinase from Bacillus sp. as plant growth promoters. J. Pure Applied Microbiol., 3: 583-596.

Burtt, E.H. and J.M. Ichida, 1999. Bacteria useful for degrading keratin. US Patent No. 6214676.

Cappuccino, J.G. and N. Sherman, 1999. Microbiology: A Laboratory Manual. 4th Edn., Addison-wesley Longman, UK., pp: 352-357.

El-Refaia, H.A., M.A. AbdelNabya, A. Gaballab, M.H. ElArabya and A.F.A. Fattaha, 2005. Improvement of the newly isolated Bacillus pumilus FH9 keratinolytic activity. Process. Biochem., 40: 2325-2332. 
Elmayergi, H.H. and R.E. Smith, 1971. Influence of growth of Streptomycese fradiae on pepsin- $\mathrm{HCl}$ digestibility and methionine content of feather meal. Can. J. Microbiol., 17: 1067-1072.

Giongo, J.L., F.S. Lucas, F. Casarin, P. Heeb and A. Brandelli, 2007. Keratinolytic protease of Bacillus species isolated from the Amazon basin showing remarkable dehairing activity. World J. Microbiol. Biotechnol., 23: 375-382.

Gupta, R. and P. Ramnani, 2006. Microbial keratinases and their prospective applications: An overview. Applied Microbio. Biotechnol., 70: 21-33.

Ionata, E., F. Canganella, G. Bianconi, Y. Benno and M. Sakamoto et al., 2008. A novel keratinase from Clostridium sporogenes bv. pennavorans bv. nov., a thermotolerant organism isolated from solfataric muds. Microbiol. Res., 163: 105-112.

Kumar, C.G. and H. Takagi, 1999. Microbial alkaline proteases: From a bioindustrial viewpoint. Biotechnol. Adv., 17: 561-594.

Lal, S., R.C. Rajak and S.K. Hasija, 1996. Biodegradation of keratin by actinomycetes inhabiting gelatin factory campus at Jablapur: Screening of isolates. Proc. Nat. Acad. Sci. India, 66: 175-180.

Lin, X., C.G. Lee, E.S. Casale and J.C.H. Shih, 1992. Purification and characterization of a keratinase from a feather-degrading Bacillus licheniformis strain. Applied Environ. Microbiol., 58: 3271-3275.

Lin, X., D.W. Kelemen, E.S. Miller and J.C.H. Shih, 1995. Nucleotide sequence and expression of kerA, the gene encoding a keratinolytic protease of Bacillus licheniformis PWD-1. Applied Environ. Microbiol., 61: 1469-1474.

Manczinger, L., M. Rozs, C.S. Vagvolgyi and F. Kevei, 2003. Isolation and characterization of a new keratinolytic Bacillus licheniformis strain. World. J. Microbiol. Biotechnol., 19: 35-39.
Radha, S. and P. Gunasekaren, 2008. Sustained expression of keratinase gene under PxylA and PamyL promoters in the recombinant Bacillus megaterium MS941. Bioresour. Technol., 99: 5528-5537.

Rai, S.K. and A.K. Mukherjee, 2010. Statistical optimization of production, purification and industrial application of a laundry detergent and organic solvent-stable subtilisin-like serine protease (Alzwiprase) from Bacillus subtilis DM-04. Biochem. Eng. J., 48: 173-180.

Rai, S.K., J.K. Roy and A.K. Mukherjee, 2010. Characterisation of a detergent-stable alkaline protease from a novel thermophilic strain Paenibacillus tezpurensis sp. nov. AS-S24-II. Applied Microbiol. Biotechnol., 85: 1437-1450.

Suntornsuk, W., J. Tongjun, P. Onnim, H. Oyama, K. Ratanakanokchai, T. Kusamran and K. Oda, 2005. Purification and characterisation of keratinase from a thermotolerant feather-degrading bacterium. World. J. Microbiol. Biotechnol., 21: 1111-1117.

Suzuki, Y., Y. Tsujimoto, H. Matsui and K. Watanabe, 2006. Decomposition of extremely hard-to-degrade animal proteins by thermophilic bacteria. J. Biosci. Bioeng., 102: 73-81.

Thys, R.C.S., F.S. Lucas, A. Riffel, P. Heeb and A. Brandelli, 2004. Characterization of a protease of a feather-degrading Microbacterium species. Lett. Applied Microbiol., 39: 181-186.

Williams, C.M., C.S. Richter, J.M. Mackenzie and J.C.H. Shih, 1990. Isolation, identification and characterization of a feather-degrading bacterium. Applied Environ. Microbial., 56: 1509-1515. 